Article

\title{
Ultrasonic-assisted fabrication and catalytic activity of CeZrAl oxide-supported Pd for the purification of gasohol exhaust
}

\author{
LIU Jianying a,b, ZHAO Ming a,*, XU Chenghua ${ }^{b}$, LIU Shengyu ${ }^{b}$, ZHANG Xueqiao ${ }^{b}$, CHEN Yaoqiang a,\# \\ a Institute of Catalytic Material Science, Sichuan University, Chengdu 610064, Sichuan, China \\ b The College of Resource and Environment, Chengdu University of Information Technology, Chengdu 610225, Sichuan, China
}

\section{A R T I C L E I N F}

\section{Article history:}

Received 11 October 2012

Accepted 13 November 2012

Published 20 April 2013

\section{Keywords:}

Ceria-zirconia-alumina

Ultrasonic

Palladium

Gasohol

Exhaust

Purification

\begin{abstract}
A B S T R A C T
CeZrAl oxides (CZA) using as the support of Pd catalyst for purification of gasohol exhausts are synthesized by co-precipitation assisted by ultrasonic vibration. CZA are characterized by surface analysis, X-ray diffraction, temperature-programmed reduction by hydrogen, oxygen storage capacity (OSC), and X-ray photoelectron spectroscopy. The results show that ultrasonic vibration promotes the formation of smaller, more uniform pores in CZA, which is beneficial to the dispersion of Pd species. Ultrasonic vibration can also improve the OSC and uniformity of the composition of CZA on its surface and in bulk. Catalytic tests demonstrate that ultrasonic treatment of CZA widens the window of the full use of oxygen from $0-0.64 \%$ to $0-1.16 \%$ of Pd-CZA catalysts in the purification of gasohol exhaust, and decreases the light-off temperature of ethanol, propane, and carbon monoxide by 30,28 , and $24^{\circ} \mathrm{C}$, respectively. Moreover, the interaction between Pd species and CZA can enhance the reaction of NO with propane and ethanol.
\end{abstract}

(C) 2013, Dalian Institute of Chemical Physics, Chinese Academy of Sciences. Published by Elsevier B.V. All rights reserved.

\section{Introduction}

Using environmentally friendly alternative fuels is one of the ways to solve the problem of increasing air pollution from automobile exhaust. Ethanol is the most widely used alternative fuel because it contains oxygen, is reproducible, shows good anti-knock characteristics, and can reduce the emission of $\mathrm{CO}$ and hydrocarbons (HCs) [1-3]. However, the use of alcohol-based fuels for automobiles will lead to new organic pollutants such as unburned ethanol, acetaldehyde, acetone, acetic acid, and ethers [4-7], which can be involved in photochemical air pollution. In addition, acetaldehyde is also a toxic compound $[8,9]$. The purification of organic contaminants produced by alcohol-based fuels has not yet been paid sufficient attention in many countries. It is well known that three-way catalysts (TWCs) are the most effective way to treat the exhaust from gasoline vehicles. However, existing TWCs have not yet been used to purify gasohol exhaust.

According to reports, the support of TWCs determines the catalyst performance and life [10]. At present, CeZrAl oxides (CZA) are the most studied support for exhaust catalysts because of their excellent textural properties, thermal stability, and oxygen storage capacity (OSC) [11-15]. The performance of CZA is closely related to its method of preparation $[10,16,17]$. Currently, CZA is typically prepared by co-precipitation [18-22] or sol-gel $[17,23]$ methods. Meanwhile, ultrasonic treatment has been successfully used in nanomaterial synthesis to make particles more uniform, increase

\footnotetext{
*Corresponding author. Tel/Fax: +86-28-85418451; E-mail: zhaoming@scu.edu.cn \#Corresponding author. Tel/Fax: +86-28-85418451; E-mail: nic7501@scu.edu.cn

This work was supported by the National Natural Science Foundation of China (21173153), Air Environmental Modeling and Pollution Controlling Key Laboratory of Sichuan Higher Education Institutes (ZZKT2012005), and Science and Technology Department of Sichuan Province (2012FZ0008).

DOI: 10.1016/S1872-2067(11)60488-9 | http://www.sciencedirect.com/science/journal/18722067 | Chin. J. Catal., Vol. 34, No. 4, April 2013
} 
specific surface area, shorten reaction time, and purify phases [24-26]. However, ultrasonic treatment has not yet been used in the synthesis of CZA. As far as the active component of automobile exhaust catalysts is concerned, palladium (Pd) exhibits excellent catalytic activity for the combustion of $\mathrm{HCs}, \mathrm{CO}$, and ethanol [27-31], so it was used here as the active species to purify gasohol exhaust.

The present work uses ultrasonic treatment to synthesize CZA. The textural, structural, and redox properties, Pd dispersion, and OSC of CZA samples prepared with and without ultrasonic treatment are investigated by surface analysis, X-ray diffraction (XRD), temperature-programmed reduction by hydrogen ( $\mathrm{H}_{2}$-TPR), oxygen pulse adsorption, and X-ray photoelectron spectroscopy (XPS). The obtained CZA oxides are also used as supports for Pd catalysts in the purification of gasohol exhausts. The catalytic activities of Pd catalysts supported on different CZA samples are investigated in detail.

\section{Experimental}

\subsection{Preparation of CZA}

All chemicals (analytical grade) were supplied by Chengdu Ke Long Chemical Reagent Factory and used as received. $\mathrm{ZrOCO}_{3}$ was first dissolved in concentrated nitric acid, and then mixed with an aqueous solution of $\mathrm{Ce}\left(\mathrm{NO}_{3}\right)_{3}$ and $\mathrm{Al}\left(\mathrm{NO}_{3}\right)_{3}$. The molar ratio of Ce:Zr:Al in the resulting solution was 2:3:5. Ammonia was slowly titrated into the above solution until $\mathrm{pH}=10$ under the vigorous agitation. The suspension was stirred at 70 ${ }^{\circ} \mathrm{C}$ for $1 \mathrm{~h}$, and then filtered, washed with distilled water, and dried at $120{ }^{\circ} \mathrm{C}$ overnight. For comparison, the same suspension was treated under ultrasonic vibration for $1 \mathrm{~h}$, and then filtered, washed with distilled water, and dried at $120{ }^{\circ} \mathrm{C}$ overnight. CZA samples were obtained after calcination in air at 600 ${ }^{\circ} \mathrm{C}$ for $3 \mathrm{~h}$. Samples prepared without and with ultrasonic treatment are denoted as CZA-S and CZA-U, respectively.

\subsection{Preparation of Pd catalysts}

CZA-S or CZA-U was added to aqueous solutions of $\mathrm{Pd}\left(\mathrm{NO}_{3}\right)_{2}$ to obtain catalysts designated Pd-CZA-S and Pd-CZA-U, respectively. The nominal Pd loading was $2.0 \mathrm{wt} \%$. The resulting powder was dried at $120^{\circ} \mathrm{C}$ for $24 \mathrm{~h}$, and then added to desired water and ground to form a slurry. The slurry was coated on honeycomb cordierite $\left(2.5 \mathrm{~cm}^{3}\right.$, Corning Ltd., New York, USA), and the precious metal content was $0.70 \mathrm{~g} / \mathrm{L}$. The sample was dried and calcined at $550{ }^{\circ} \mathrm{C}$ for $3 \mathrm{~h}$ in air to obtain the monolithic Pd-CZA-S or Pd-CZA-U catalyst.

\subsection{Characterization}

The texture of CZA was characterized by the Brunauer-Emmett-Teller (BET) method using an SSA-4200 analyzer (Builder Co., Beijing, China) at $-196{ }^{\circ} \mathrm{C}$ following degassing at room temperature for $2 \mathrm{~h}$. The structure of CZA was determined by powder XRD on an X-ray diffractometer (DX-1000, Dandong, China) in the range of $2 \theta=10^{\circ}-80^{\circ}$ using $\mathrm{Cu} K \alpha$ radi- ation $(\lambda=0.154 \mathrm{~nm})$, and operating at $40 \mathrm{kV}$ and $25 \mathrm{~mA}$. $\mathrm{H}_{2}$-TPR experiments were performed in a quartz apparatus equipped with a thermal conductivity detector (TCD) to monitor the consumption of $\mathrm{H}_{2}$. Each sample $(100 \mathrm{mg}$ ) was first pretreated at $500{ }^{\circ} \mathrm{C}$ for $1 \mathrm{~h}$ under a flow of $\mathrm{N}_{2}\left(30 \mathrm{~cm}^{3} / \mathrm{min}\right)$. After cooling, the samples were heated from room temperature to $800{ }^{\circ} \mathrm{C}$ with a $5 \% \mathrm{H}_{2}-95 \% \mathrm{~N}_{2}$ mixed gas (flow rate of 30 $\mathrm{cm}^{3} / \mathrm{min}$, temperature ramp $10{ }^{\circ} \mathrm{C} / \mathrm{min}$ ), and the consumption of $\mathrm{H}_{2}$ was detected by a TCD. The total OSC was measured by oxygen pulse adsorption. Each sample $(200 \mathrm{mg})$ was reduced at $550{ }^{\circ} \mathrm{C}$ for $60 \mathrm{~min}$ under a flow of $\mathrm{H}_{2}$ of $30 \mathrm{~cm}^{3} / \mathrm{min}$ and then cooled to $200{ }^{\circ} \mathrm{C}$ under a flow of $\mathrm{N}_{2}\left(20 \mathrm{~cm}^{3} / \mathrm{min}\right)$. Then, a pulse of oxygen $(27.0 \mu \mathrm{mol})$ was injected into the sample until no consumption of $\mathrm{O}_{2}$ was detected by the TCD. The dispersion of $\mathrm{Pd}$ was evaluated by $\mathrm{CO}$ pulse chemisorption at room temperature assuming a chemisorption stoichiometry of $1: 1$ between CO and Pd. Before chemisorption, Pd catalyst (300 mg) in a U-type quartz tube was first activated at $500{ }^{\circ} \mathrm{C}$ in a flow of $5 \% \mathrm{H}_{2}-95 \% \mathrm{~N}_{2}$ for $1 \mathrm{~h}$. The remnant $\mathrm{H}_{2}$ was removed under a flow of $\mathrm{Ar}$ at $550{ }^{\circ} \mathrm{C}$ for $30 \mathrm{~min}$, and then the sample was cooled to room temperature. XPS measurements were carried out on a spectrometer (Kratos XSAM 800, Manchester, UK) equipped with a Mg $K_{\alpha}$ source. The binding energy (BE) correction was performed using the $\mathrm{C} 1 \mathrm{~s}$ peak of adventitious carbon at 284.8 $\mathrm{eV}$ as a reference.

\subsection{Catalytic tests}

The catalytic activity of Pd-CZA-S or Pd-CZA-U was evaluated by the purification of simulated gasohol exhaust in a fixed-bed continuous flow microreactor. The simulated exhaust contained an adjustable mixture of CO (1.1\%-1.2\%), propane $\left(\mathrm{C}_{3} \mathrm{H}_{8} ; 0.06-0.07 \%\right)$, nitric oxide (NO; $\left.0.07 \%-0.08 \%\right), \mathrm{O}_{2}$ (0-15\%), ethanol $(0.03 \%-0.04 \%)$, and $\mathrm{N}_{2}$ (balance) using mass-flow controllers. Typically, the monolithic catalyst was placed in a quartz tube reactor and activated in air at $350{ }^{\circ} \mathrm{C}$ for $1 \mathrm{~h}$. After the temperature was adjusted to the desired value, the simulated exhaust gas with a gas hourly space velocity (GHSV) of $30000 \mathrm{~h}^{-1}$ was passed through the catalyst bed. The tested reaction temperature range was $100-400{ }^{\circ} \mathrm{C}$. The organic products were analyzed by gas chromatography (GC-2000, Shanghai, China) equipped with a flame ionization detector (FID) and Porapak Q column. The amounts of CO, HCs, $\mathrm{NO}, \mathrm{O}_{2}$, and $\mathrm{CO}_{2}$ were analyzed online using a five-component vehicle exhaust gas analyzer (FGA-4001, Foshan, Guangdong, China).

\section{Results and discussion}

\subsection{Texture of CZA samples}

The textural properties of the supports are presented in Table 1. CZA-U possesses smaller pore volume and pore size $(0.27$ $\mathrm{cm}^{3} / \mathrm{g}$ and $6.14 \mathrm{~nm}$, respectively) than CZA-S $\left(0.39 \mathrm{~cm}^{3} / \mathrm{g}\right.$ and $9.08 \mathrm{~nm}$, respectively). This shows that ultrasonic treatment promotes the formation of small pores, resulting in reduced pore volume, and increased surface area. 
Table 1

Textural properties and OSC of supports and Pd dispersion of catalysts.

\begin{tabular}{lcccccc}
\hline Sample & $\begin{array}{c}A_{\mathrm{BET}} \\
\left(\mathrm{m}^{2} / \mathrm{g}\right)\end{array}$ & $\begin{array}{c}V_{\mathrm{p}} \\
\left(\mathrm{cm}^{3} / \mathrm{g}\right)\end{array}$ & $\begin{array}{c}D_{\text {mean }} \\
(\mathrm{nm})\end{array}$ & $\begin{array}{c}\text { OSC } \\
(\mu \mathrm{mol} / \mathrm{g})\end{array}$ & $\begin{array}{c}\text { Pd dispersion } \\
(\%)\end{array}$ & $\begin{array}{c}\text { Pd particle } \\
\text { size }(\mathrm{nm})\end{array}$ \\
\hline CZA-S & 169.9 & 0.39 & 9.08 & 263 & 39.0 & 1.99 \\
CZA-U & 174.6 & 0.27 & 6.14 & 291 & 52.2 & 1.48 \\
\hline
\end{tabular}

$A_{\mathrm{BET}}$ : specific surface area; $V_{\mathrm{p}}$ : pore volume; $D_{\text {mean }}$ : average pore diameter.

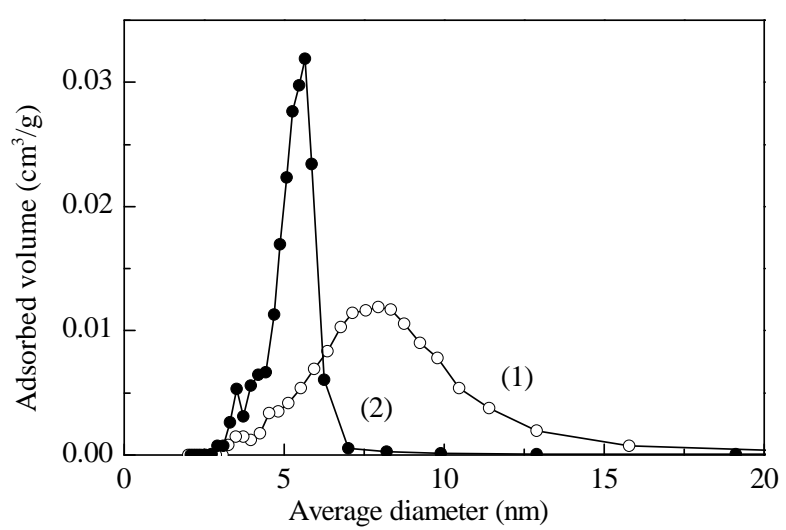

Fig. 1. Pore distribution curves of the supports. (1) CZA-S; (2) CZA-U.

Figure 1 shows the pore-size distribution curves of the supports. The pore distribution is very narrow and homogeneous for CZA-U, probably because of the cavitation-induced effect of ultrasonic treatment [32,33]. Propagation of acoustic vibrations through the liquid CZA hydroxide precursor can cause cavitation bubbles to form. These bubbles can concentrate the acoustic energy within very small spatial domains in a medium [32], which makes pores smaller and uniform.

\subsection{Pd dispersion in the catalysts}

The dispersion of $\mathrm{Pd}$ in the Pd-CZA catalysts is also listed in Table 1. Pd-CZA-U possesses a higher Pd dispersion (52.2\%) with a smaller Pd particle size $(1.48 \mathrm{~nm})$ than Pd-CZA-S, probably because of the higher surface area of CZA-U and the smaller Pd particles interacting strongly with the support [34]. A good correlation is observed between Pd dispersion and catalytic activity, and the better dispersion of Pd should be one of the reasons for the excellent activity of Pd-CZA-U [35].

\section{3. $X R D$}

XRD patterns of the supports (Fig. 2) revealed that both samples exhibit the characteristic peaks of a cubic ceria-zirconia (CZ) solid solution. No obvious characteristic diffraction peaks for aluminum species are observed, which is attributed to the incorporation of $\mathrm{Al}^{3+}$ into the $\mathrm{CZ}$ lattice $[36,37]$. CZA-U shows broader diffraction peaks than CZA-S, indicating a decrease of crystallite size [38] resulting from the effect of ultrasonic vibration during its preparation. Using the half-band width of the reflection peak at $2 \theta=29^{\circ}$ characteristic of the (111) crystal plane for a CZ solid solution, the crystal size of CZA-U can be calculated with the Scherrer formula as $3.5 \mathrm{~nm}$,

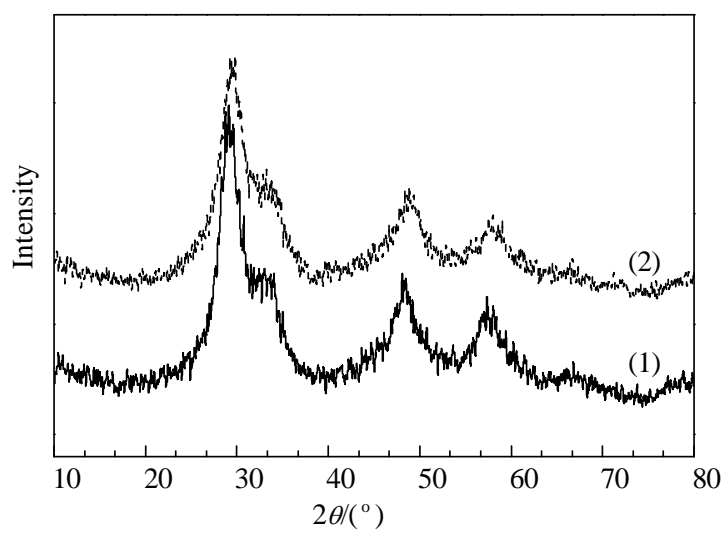

Fig. 2. XRD patterns of the supports. (1) CZA-S; (2) CZA-U.

which is smaller than that of CZA-S (4.1 nm). This result further confirms that ultrasonic treatment induces the formation of smaller CZA particles, which is consistent with the results of BET analysis.

\section{4. $H_{2}-T P R$}

The $\mathrm{H}_{2}$-TPR profiles of the supports (Fig. 3(a)) show that both CZA-S and CZA-U have two main $\mathrm{H}_{2}$ consumption peaks at about 450 and $550{ }^{\circ} \mathrm{C}$ (denoted as $\alpha$ and $\beta$ ) that are attributed to the reduction of surface and subsurface $\mathrm{Ce}^{4+}$, respectively [39]. CZA-U has a larger total peak area than CZA-S and especially a more intense $\alpha$ peak, indicating that more Ce species are present on the surface of CZA-U. As the surface Ce increases, the OSC of CZA improves, which is in accordance with the OSC results in Table 1. Meanwhile, an increase of the reduction temperature of Ce species in CZA-U is related to strengthening

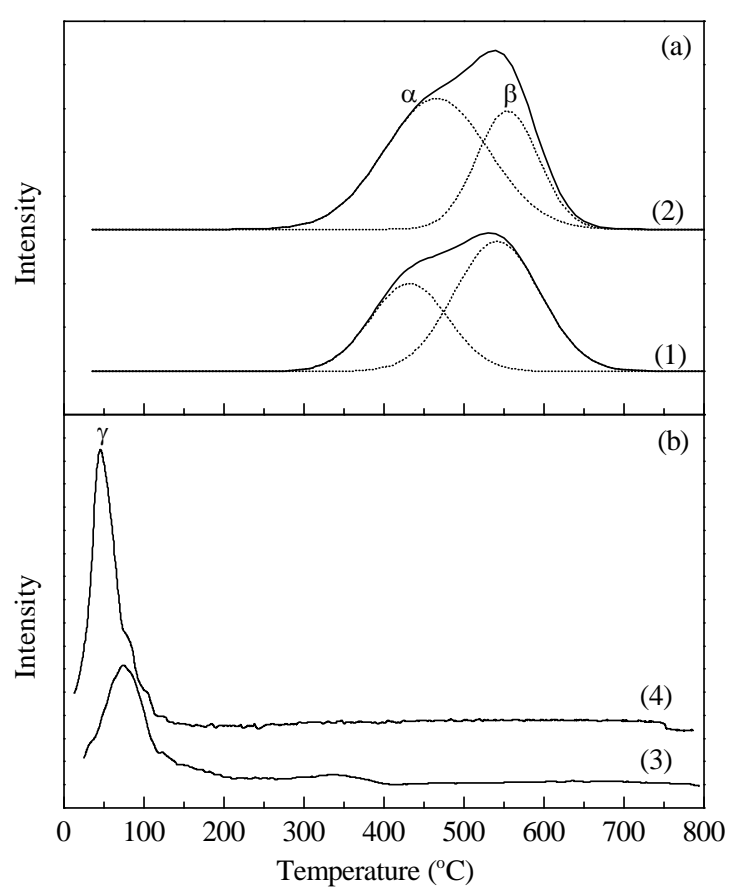

Fig. 3. $\mathrm{H}_{2}$-TPR profiles of the supports (a) and catalysts (b). (1) CZA-S; (2) CZA-U; (3) Pd-CZA-S; (4) Pd-CZA-U. 
Table 2

Binding energy (eV) of core electrons of elements in the supports and catalysts.

\begin{tabular}{|c|c|c|c|c|c|c|c|c|}
\hline \multirow{2}{*}{ Sample } & \multicolumn{2}{|c|}{ Ce $3 d_{5 / 2}$} & \multirow{2}{*}{$\operatorname{Zr} 3 d_{5 / 2}$} & \multirow{2}{*}{ Al $2 p$} & \multirow{2}{*}{$\operatorname{Pd} 3 d_{5 / 2}$} & \multicolumn{3}{|c|}{$01 s$} \\
\hline & $\mathrm{Ce}^{4+}$ & $\mathrm{Ce}^{n+}$ & & & & $\Pi_{1}$ & $\Pi_{2}$ & $\Pi_{3}$ \\
\hline CZA-S & 882.7 & - & 181.4 & 74.0 & - & 529.1 & 530.4 & 531.7 \\
\hline CZA-U & 882.9 & - & 181.8 & 73.8 & - & 529.4 & 530.7 & 532.0 \\
\hline Pd-CZA-S & 882.7 & 886.1 & 181.8 & 74.1 & 336.7 & 530.0 & 531.2 & 532.3 \\
\hline Pd-CZA-U & 882.3 & 884.4 & 181.8 & 74.1 & 336.4 & 529.9 & 531.3 & 532.6 \\
\hline
\end{tabular}

of Ce-O formed under ultrasonic treatment.

Obviously, the presence of Pd lowers the reduction temperature significantly, indicating that metal-support interactions occur between Pd and CZA (Fig. 3(b)). This phenomenon is often interpreted in terms of the well-known spillover of hydrogen from $\mathrm{Pd}$ to $\mathrm{Ce}$ [40]. The $\mathrm{H}_{2}$-TPR profiles of the catalysts (Fig. 3(b)) show a large $\mathrm{H}_{2}$ consumption peak below $100{ }^{\circ} \mathrm{C}$, which is ascribed to the reduction of $\mathrm{PdO}$ and species related to $\mathrm{PdO}-\mathrm{CeO}_{2}$ interactions [41]. Moreover, the reduction temperature of $\mathrm{PdO}$ on CZA-U is about $27{ }^{\circ} \mathrm{C}$ lower than that of $\mathrm{Pd}-\mathrm{CZA}-\mathrm{S}$, indicating that $\mathrm{Pd}$ supported on CZA-U is reduced more easily because of the smaller particles of CZA [42]. The Pd-CZA-U catalyst exhibits a higher $\mathrm{H}_{2}$ consumption peak related to $\mathrm{Pd}$ species, indicating there is more $\mathrm{PdO}$ on this support because ultrasonic-assisted synthesis improves the dispersion of CZA [43] and increases the concentration of Ce species, as mentioned above. Apparently, ultrasonic vibration treatment during the preparation of the CZA support can significantly affect the redox properties of the Pd catalyst.

\subsection{XPS}

XPS measurements were obtained to further investigate the properties of the supports and catalysts. The BE data for $\mathrm{Pd}, \mathrm{Ce}$, and $\mathrm{O}$ is listed in Table 2 . The BE of Ce $3 d_{5 / 2}$ for both supports was about $882.7 \mathrm{eV}$, indicating Ce species are mainly in the form of $\mathrm{Ce}^{4+}$ [44]. However, the presence of $\mathrm{Pd}$ in the catalysts can lead to the presence of Ce species at 886.1 and $884.4 \mathrm{eV}$. The former is assigned to $\mathrm{Ce}^{3+}$ [45], and the latter corresponds to $\mathrm{Ce}$ in $\mathrm{CePd}_{3}$ [46] caused by the strong interaction between small PdO particles with Ce in CZA-U. It has been reported that the $\mathrm{BE}$ of $\mathrm{PdO}$ and metallic $\mathrm{Pd}^{0}$ are 336.8 and $335.1-335.3 \mathrm{eV}$, respectively $[47,48]$. In this work, the $\mathrm{BE}$ of $\mathrm{Pd} 3 d_{5 / 2}$ for Pd-CZA-S and Pd-CZA-U are 336.7 and $336.4 \mathrm{eV}$, respectively. These values indicate that $\mathrm{Pd}$ is partially oxidized, which probably corresponds to a dispersed state [49]. Meanwhile, three different oxygen bands can be discerned at 529.1-530.0, 530.4-531.2, and 531.7-532.5 eV. The band at 529.1-530.0 eV can be assigned to oxygen species bonded to Ce (denoted as $\Pi_{1}$ )
[35,50]. The other two peaks at 530.4-531.2 and 531.7-532.5 $\mathrm{eV}$ are assigned to lattice oxygen (denoted as $\Pi_{2}$ ) and surface hydroxyl groups (denoted as $\Pi_{3}$ ) [35], respectively. From Table 2 , the presence of Pd increases the BE of oxygen species at $\Pi_{1}$, $\Pi_{2}$, and $\Pi_{3}$, which is a result of the interaction between Pd and the supports.

The surface atomic ratios are shown in Table 3. The oxygen species in CZA-U can transfer from $\Pi_{1}$ and $\Pi_{3}$ to $\Pi_{2}$ during ultrasonic treatment, resulting in a higher OSC for CZA-U as mentioned above. Another noticeable point is that the measured ratio of $\mathrm{Ce} / \mathrm{Zr}$ for $\mathrm{CZA}-\mathrm{U}$ is equal to the theoretical one, indicating that ultrasonic vibration is beneficial to forming a uniform surface and bulk composition of CZA. Meanwhile, the ratios of $\mathrm{Pd} / \mathrm{Ce}, \mathrm{Pd} /(\mathrm{Ce}+\mathrm{Zr}+\mathrm{Al})$, and $\mathrm{Pd} / \mathrm{O}$ in $\mathrm{Pd}-\mathrm{CZA}-\mathrm{U}$ are all greater than those in Pd-CZA-S, indicating that more $\mathrm{Pd}$ species are exposed on the surface of Pd-CZA-U than in Pd-CZA-S. This result is consistent with the results of $\mathrm{Pd}$ dispersion and $\mathrm{H}_{2}$-TPR discussed above.

\subsection{Purification of gasohol exhaust}

\subsubsection{Effect of $\mathrm{O}_{2}$ concentration}

The effects of the $\mathrm{O}_{2}$ concentration in gasohol exhaust on the conversion of $\mathrm{CO}, \mathrm{C}_{3} \mathrm{H}_{8}, \mathrm{NO}$, and ethanol at $350{ }^{\circ} \mathrm{C}$ over Pd-CZA-S and Pd-CZA-U and $\mathrm{O}_{2}$ use were investigated. As shown in Fig. 4, NO is completely transformed when the gasohol exhaust lacks $\mathrm{O}_{2}$, indicating that $\mathrm{NO}$ mainly acts as the oxidant for the oxidation of $\mathrm{CO}, \mathrm{C}_{3} \mathrm{H}_{8}$, and ethanol over both catalysts in fuel-rich conditions. However, NO conversion decreased rapidly when the $\mathrm{O}_{2}$ concentration was above a certain value, showing that $\mathrm{O}_{2}$ exhibits a stronger oxidation capacity than NO. Therefore, the presence of $\mathrm{O}_{2}$ in high concentration hinders the removal of NO. At the same time, the $\mathrm{O}_{2}$ concentration window for the full use of $\mathrm{O}_{2}$ over Pd-CZA-U $(0-1.16 \%)$ is broader than that over Pd-CZA-S (0-0.64\%). This result is assigned to the higher OSC of Pd-CZA-U. Moreover, the conversions of $\mathrm{CO}, \mathrm{C}_{3} \mathrm{H}_{8}, \mathrm{NO}$, and ethanol over Pd-CZA-U are also higher than those over Pd-CZA-S in the presence of $\mathrm{O}_{2}$. Overall, the Pd catalyst supported on CZA synthesized by ultrasonic

Table 3

Surface atomic ratios of supports and catalysts obtained from XPS.

\begin{tabular}{lccccccc}
\hline Sample & $\Pi_{1}: \Pi_{2}: \Pi_{3}$ & $\mathrm{Pd} / \mathrm{Ce}$ & $\mathrm{Pd} /(\mathrm{Ce}+\mathrm{Zr}+\mathrm{Al})$ & $\mathrm{Pd} / 0$ & $\mathrm{Ce}^{n+} / \mathrm{Ce}^{4+}$ & $\mathrm{Ce} / \mathrm{Zr}$ & \multicolumn{2}{c}{$\mathrm{Calculated}$} \\
\hline CZA-S & $25.2: 42.5: 32.3$ & - & - & - & - & 0.43 \\
CZA-U & $22.1: 46.2: 31.7$ & - & - & - & - & 0.67 \\
Pd-CZA-S & $30.8: 46.6: 22.6$ & 0.29 & 0.014 & 0.007 & 0.511 & - \\
Pd-CZA-U & $29.4: 47.5: 23.1$ & 0.59 & 0.022 & 0.012 & 0.365 & - & - \\
\hline
\end{tabular}




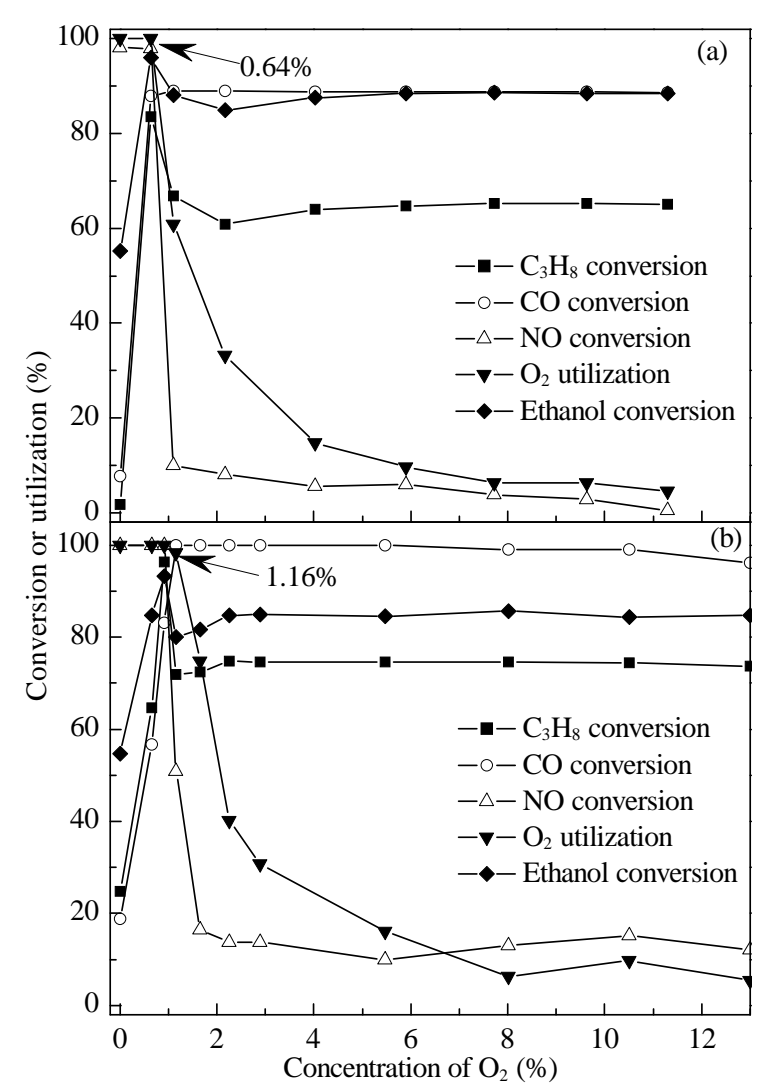

Fig. 4. Conversion of ethanol, $\mathrm{C}_{3} \mathrm{H}_{8}, \mathrm{CO}$, and $\mathrm{NO}$ at different $\mathrm{O}_{2}$ concentrations. (a) Pd-CZA-S; (b) Pd-CZA-U.

treatment exhibits excellent catalytic performance for the purification of gasohol exhaust.

\subsubsection{Effect of reaction temperature}

Figure 5 presents the effect of reaction temperature on the conversion of $\mathrm{C}_{3} \mathrm{H}_{8}, \mathrm{CO}$, NO, and ethanol over Pd-CZA-S and Pd-CZA-U. The temperature at which a conversion reaches $50 \%$ $\left(T_{50}\right)$ is used as an index of catalytic activity. Pd-CZA-U exhibits lower $T_{50}$ towards ethanol, $\mathrm{C}_{3} \mathrm{H}_{8}$, and $\mathrm{CO}$ than Pd-CZA-S by 30 , 28 , and $24{ }^{\circ} \mathrm{C}$, respectively. This shows that Pd-CZA-U exhibits higher catalytic activity than Pd-CZA-S, probably because $\mathrm{Pd}$ is better dispersed and more Pd species are exposed on the sur- face of CZA-U. Moreover, a rapid increase of NO conversion can be observed in the temperature range of $150-240{ }^{\circ} \mathrm{C}$, in which the $\mathrm{CO}$ conversion increases remarkably. This result indicates that the reaction $\mathrm{CO}+2 \mathrm{NO} \rightarrow \mathrm{N}_{2}+\mathrm{CO}_{2}$ can take place over Pd-CZA-S promoted by the $\mathrm{Ce}^{3+}$ species detected by XPS, which is consistent with previously reported results [51]. However, NO conversion begins to decrease over $240{ }^{\circ} \mathrm{C}$ because $\mathrm{CO}$ can react completely with $\mathrm{O}_{2}$. Therefore, Pd-CZA-S shows better catalytic activity for NO at low temperature. The reduction of NO over Pd-CZA-U mainly occurs in the temperature range of 250-350 ${ }^{\circ} \mathrm{C}$, along with increasing conversion of ethanol and $\mathrm{C}_{3} \mathrm{H}_{8}$, so NO conversion may be caused by the two reactions $\mathrm{C}_{3} \mathrm{H}_{8}+2 \mathrm{NO}+4 \mathrm{O}_{2} \rightarrow \mathrm{N}_{2}+3 \mathrm{CO}_{2}+4 \mathrm{H}_{2} \mathrm{O}$ and $\mathrm{C}_{2} \mathrm{H}_{5} \mathrm{OH}+2 \mathrm{NO}+2 \mathrm{O}_{2}$ $\rightarrow \mathrm{N}_{2}+2 \mathrm{CO}_{2}+3 \mathrm{H}_{2} \mathrm{O}$.

\section{Conclusions}

CZA synthesized by co-precipitation assisted by ultrasonic treatment exhibits better textural, OSC, and redox properties than that prepared without exposure to ultrasound. Ultrasonic treatment improves the uniformity of the surface and bulk composition of CZA, increasing the bonding between $\mathrm{Ce}, \mathrm{Zr}$, and O. A Pd catalyst supported by a CZA sample prepared by ultrasonic treatment exhibited higher catalytic activity towards the conversion of ethanol, $\mathrm{C}_{3} \mathrm{H}_{8}, \mathrm{CO}$ with $T_{50}$ decreased by 30,28 , and $24{ }^{\circ} \mathrm{C}$, respectively, compared with those of a catalyst on a support prepared without ultrasonic treatment. The reactions $\mathrm{C}_{3} \mathrm{H}_{8}+2 \mathrm{NO}+4 \mathrm{O}_{2} \rightarrow \mathrm{N}_{2}+3 \mathrm{CO}_{2}+4 \mathrm{H}_{2} \mathrm{O}$ and $\mathrm{C}_{2} \mathrm{H}_{5} \mathrm{OH}+2 \mathrm{NO}+$ $2 \mathrm{O}_{2} \rightarrow \mathrm{N}_{2}+2 \mathrm{CO}_{2}+3 \mathrm{H}_{2} \mathrm{O}$ are promoted by the improved interactions between $\mathrm{Pd}$ species and CZA prepared with ultrasonic treatment.

\section{References}

[1] Demirbas A. Energ Policy, 2007, 35: 4661

[2] Hsieh W D, Chen R H, Wu T L, Lin T H. Atmos Environ, 2002, 36: 403

[3] Cooney C P, Worm J J, Naber J D. Energy Fuels, 2009, 23: 2319

[4] Corrêa S M, Martins E M, Arbilla G. Atmos Environ, 2003, 37: 23

[5] Graham L A, Belisle S L, Baas C L. Atmos Environ, 2008, 42: 4498

[6] Di Y, Cheung C S, Huang Z H. Sci Total Environ, 2009, 407: 835

[7] Corrêa S M, Arbilla G, Martins E M, Quitério S L, de Souza Guimarães C, Gatti L V. Atmos Environ, 2010, 44: 2302

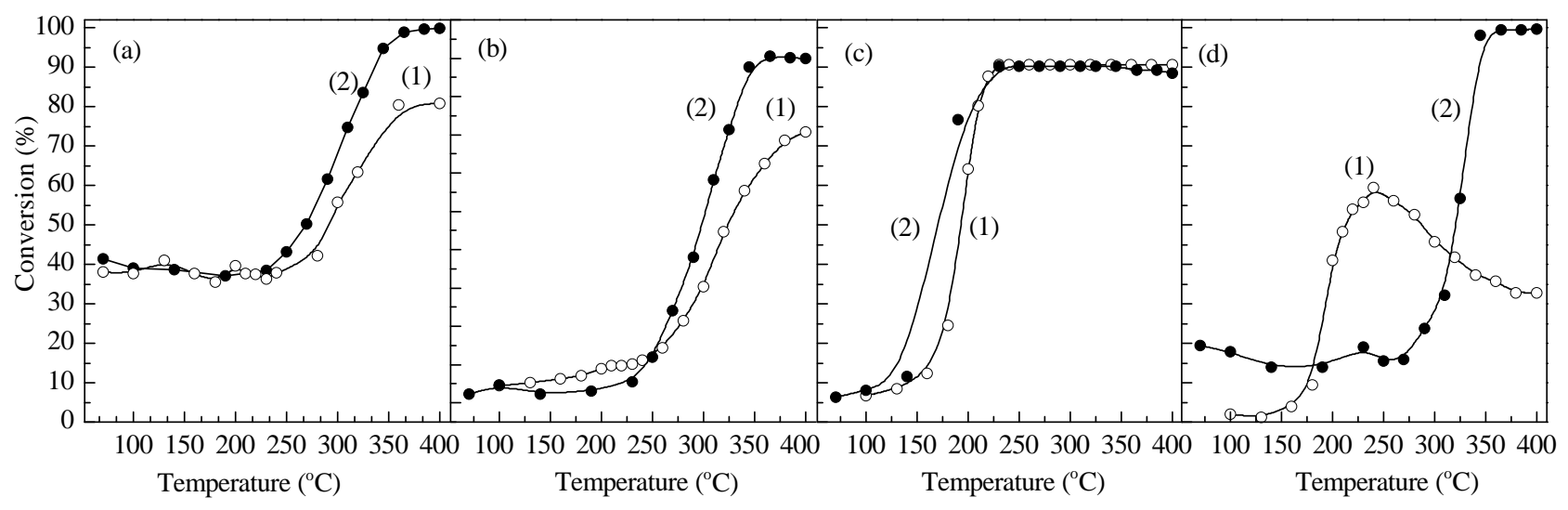

Fig. 5. Conversion of ethanol (a), $\mathrm{C}_{3} \mathrm{H}_{8}$ (b), $\mathrm{CO}$ (c), and NO (d) at different temperatures over Pd-CZA-S (1) and Pd-CZA-U (2). 


\section{Graphical Abstract}

Chin. J. Catal., 2013, 34: 751-757 doi: 10.1016/S1872-2067(11)60488-9

Ultrasonic-assisted fabrication and catalytic activity of CeZrAl oxide-supported Pd for the purification of gasohol exhaust

LIU Jianying, ZHAO Ming*, XU Chenghua, LIU Shengyu, ZHANG Xueqiao, CHEN Yaoqiang*

Sichuan University; Chengdu University of Information Technology

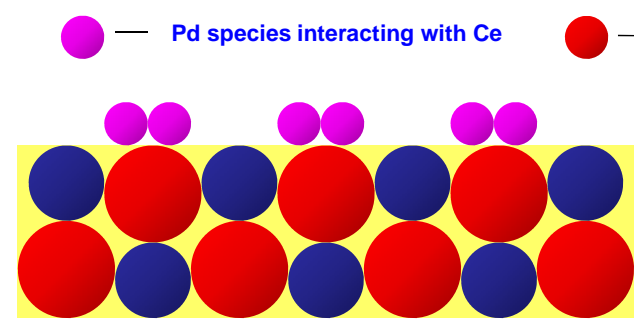

Without ultrasonic vibration

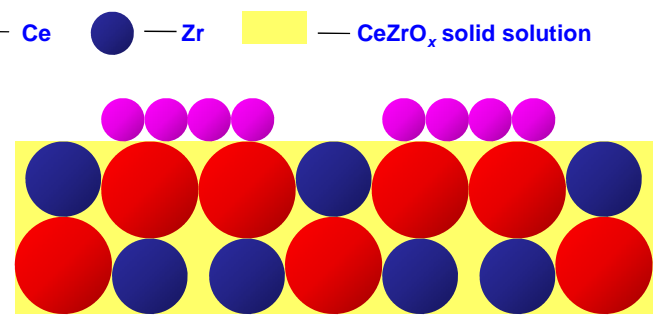

With ultrasonic vibration

Ultrasonic vibration leads to more Ce on the surface of $\mathrm{CeZrO}_{x}$ solid solution, and therefore more Pd species that interact with Ce.

[8] Baez A P, Belmont R, Padilla H. Enviro Pollut, 1995, 89: 163

[9] Poulopoulos S G, Samaras D P, Philippopoulos C J. Atmos Environ, 2001, 35: 4399

[10] Wu X D, Fan J, Ran R, Yang J, Weng D. J Alloys Compd, 2005, 395: 135

[11] Zhao M, Chen Sh H, Zhang X Y, Gong M Ch, Chen Y Q. J Rare Earths, 2009, 27: 728

[12] Wei Z L, Li H M, Zhang X Y, Yan Sh H, Lü Zh, Chen Y Q, Gong M Ch.J Alloys Compd, 2008, 455: 322

[13] Morikawa A, Suzuki T, Kanazawa T, Kikuta K, Suda A, Shinjo H. Appl Catal B, 2008, 78: 210

[14] Kaspar J, Fornasiero P, Hickey N. Catal Today, 2003, 77: 419

[15] Kaspar J, Fornasiero P, Graziani M. Catal Today, 1999, 50: 285

[16] Zhao B, Li G F, Ge Ch H, Wang Q Y, Zhou R X. Appl Catal B, 2010, 96: 338

[17] Frolova E V, Ivanovskaya M I, Kosareva Y A. Thin Solid Films, 2006, 495: 139

[18] Li H M, Zhu Q C, Li Y L, Gong M Ch, Chen Y D, Wang J L, Chen Y Q. J Rare Earths, 2010, 28: 79

[19] Pan Y L, Wen Y Y, Chen Y Q, Gong M Ch. Chem J Chin Univ (潘依浪, 温怡芸, 陈耀强, 龚茂初. 高等学校化学学报), 2009, 30: 337

[20] Li H M, Zhou J F, Zhu Q C, Zeng S H, Wei Z L, Chen Y Q, Gong M Ch. Chem J Chin Univ (李红梅, 周菊发, 祝清超, 曾少华, 魏振玲, 陈耀强, 龚茂初. 高等学校化学学报), 2009, 30: 2484

[21] Shen M Q, Yang M, Wang J, Wen J, Zhao M W, Wang W L. J Phys Chem C, 2009, 113: 3212

[22] Mei D J, Chen Y Q, Zhong J B, Wei Z L, Ma D, Gong M Ch. J Rare Earth, 2007, 25: 311

[23] Frolova E V, Ivanovskaya M I, Hlushonak H K. Opt Mater, 2006, 28: 660

[24] Yao S Y, Xie Z H. J Mater Process Technol, 2007, 186: 54

[25] Pinjari D V, Pandit A B. Ultrason Sonochem, 2011, 18: 1118

[26] Tu Y B, Luo J Y, Meng M, Wang G, He J J. Int J Hydrogen Energy, 2009, 34: 3743

[27] Zheng H T, Li Y L, Chen S X, Shen P K. J Power Sources, 2006, 163: 371

[28] Dimos M M, Blanchard G J.J Phys Chem C, 2010, 114: 6019

[29] Greca M C, Moraes C, Morelli M R, Segadaes A M. Appl Catal A, 1999, 179: 87
[30] Galvita V V, Belyaev V D, Semikolenov V A, Tsiakaras P, Frumin A, Sobyanin V A. React Kinet Catal Lett, 2002, 76: 343

[31] Davidson J M, McGregor C M, Doraiswamy L K. Ind Eng Chem Res, 2001, 40: 108

[32] Baranchikov A Y, Ivanov V K, Tretyakov Y D. Uspekhi Khimii, 2007, 76: 147

[33] Bang J H, Suslick K S. Adv Mater, 2010, 22: 1039

[34] Wang H R, Chen Y Q, Zhang Q L, Zhu Q Ch, Gong M Ch, Zhao M.J Nat Gas Chem, 2009, 18: 211

[35] Zhang X Y, Long E Y, Li Y L, Zhang L J, Guo J X, Gong M Ch, Chen Y Q. J Mol Catal A, 2009, 308: 73

[36] Zhao B, Yang C Q, Wang Q Y, Li G F, Zhou R X. J Alloys Compd, 2010, 494: 340

[37] Cai L, Zhao M, Pi Zh, Gong M Ch, Chen Y Q. Chin J Catal (蔡黎, 赵明, 皮展, 龚茂初, 陈耀强. 催化学报), 2008, 29: 108

[38] Wang J Q, Shen M Q, An Y, Wang J. Catal Commun, 2008, 10: 103

[39] He H, Dai H X, Au C T. Catal Today, 2004, 90: 245

[40] Hamoudi S, Sayari A, Belkacemi K, Bonneviot L, Larachi F. Catal Today, 2000, 62: 379

[41] Zhu H Q, Qin Z F, Shan W J, Shen W J, Wang J G. J Catal, 2004, 225 : 267

[42] Wang N, Chu W, Huang L Q, Zhang T. J Nat Gas Chem, 2010, 19: 117

[43] Wahlberg A, Pettersson L J, Bruce K, Andersson M, Jansson K. Appl Catal B, 1999, 23: 271

[44] Bera S, Mittal V K, Krishnan R V, Saravanan T, Velmurugan S, Nagarajan K, Narasimhan S V.J Nucl Mater, 2009, 393: 120

[45] Long Q Cai M, Rogers J D, Rong H L, Li J R, Jiang L. Nanotech, 2007, 18: 1

[46] Padilla J M, Del Angel G, Navarrete J. Catal Today, 2008, 133-135: 541

[47] de la Peña O'Shea V A, Alvarez-Galvan M C, Requies J, Barrio V L, Arias P L, Cambra J F, Güemez M B, Fierro J L G. Catal Commun, 2007, 8: 1287

[48] Otto K, Haack L P, deVries J E. Appl Catal B, 1992, 1: 1

[49] Thevenin P 0, Alcalde A, Pettersson L J, Järås S G, Fierro J L G. J Catal, 2003, 215: 78

[50] Ma Y Ch, Ge Q J, Li W Zh, Xu H Y. Appl Catal B, 2009, 90: 99

[51] Fornasiero P, Balducci G, Kaspar J, Meriani S, di Monte R, Graziani M. Catal Today, 1996, 29: 47 


\title{
超声辅助合成铈锆铝氧化物及其负载 Pd 催化剂对乙醇汽油车尾气的净化性能
}

\author{
刘建英 ${ }^{\mathrm{a}, \mathrm{b}}$, 赵 明 $\mathrm{a}^{\mathrm{*}}{ }^{*}$, 徐成华 ${ }^{\mathrm{b}}$, 刘盛余 ${ }^{\mathrm{b}}$, 张雪乔 ${ }^{\mathrm{b}}$ ，陈耀强 ${ }^{\mathrm{a}, \#}$ \\ a四川大学催化材料研究所, 四川成都 610064 \\ b成都信息工程学院资源环境学院, 四川成都 610225
}

摘要: 在共沉淀法的基础上辅助以超声制备了铈锆铝复合氧化物 (CZA), 采用比表面分析仪、 $X$ 射线衍射、程序升温还原、储氧 量和 X 射线光电子能谱对材料进行了表征. 结果表明, 超声振荡有助于小而均匀的孔生成, 有利于 Pd 物种的分散; 超声振荡还 能提高 CZA 的储氧量, 使材料的表面组成与体相组成趋于一致. 催化活性测试表明, 材料经过超声处理的 Pd-CZA 净化乙醇汽 油车尾气时, 可以将氧气的完全利用窗口从 $0 \sim 0.64 \%$ 拓宽至 $0 \sim 1.16 \%$; 并且使乙醇、 $\mathrm{C}_{3} \mathrm{H}_{8}$ 和 $\mathrm{CO}$ 起燃温度分别下降了 30,28 和 $24{ }^{\circ} \mathrm{C}$. 此外, $\mathrm{Pd}$ 物种与 $\mathrm{CZA}-\mathrm{U}$ 的相互作用有利于 $\mathrm{NO}$ 与 $\mathrm{C}_{3} \mathrm{H}_{8}$ 和 $\mathrm{C}_{2} \mathrm{H}_{5} \mathrm{OH}$ 的反应.

关键词: 铈锆铝; 超声; 钯; 乙醇汽油; 尾气; 净化

收稿日期: 2012-10-11. 接受日期: 2012-11-13. 出版日期: 2013-04-20.

*通讯联系人. 电话/传真: (028)85418451; 电子信箱: zhaoming@scu.edu.cn

\#通讯联系人. 电话/传真: (028)85418451; 电子信箱: nic7501@scu.edu.cn

基金来源: 国家自然科学基金 (21173153); “大气环境模拟与污染控制”四川省高校重点实验室 (ZZKT2012005); 四川省科技厅 (2012FZ0008).

本文的英文电子版由Elsevier出版社在ScienceDirect上出版(http://www.sciencedirect.com/science/journal/18722067). 